\title{
Dietary and anthropometric indicators of nutritional status in relation to Helicobacter pylori infection in a paediatric population
}

\author{
Mariana A. Janjetic ${ }^{1,2,3 *}$, Paula Mantero ${ }^{1}$, Eduardo Cueto Rua ${ }^{4}$, Norma Balcarce ${ }^{4}$, \\ Gerardo Zerbetto de Palma ${ }^{5}$, Mariana Catalano ${ }^{5}$, Marcela B. Zubillaga ${ }^{1}$, José R. Boccio ${ }^{1}$ and \\ Cinthia G. Goldman ${ }^{1,3}$ \\ ${ }^{1}$ Laboratory of Stable Isotopes Applied to Biology and Medicine, Physics Department, School of Pharmacy and Biochemistry, \\ University of Buenos Aires, Junin 956, 1113 Buenos Aires, Argentina \\ ${ }^{2}$ Nutrition Department, School of Medicine, University of Buenos Aires, Marcelo T de Alvear 2202, \\ 1122 Buenos Aires, Argentina \\ ${ }^{3}$ Argentine National Scientific and Technological Research Council (CONICET), Rivadavia 1917, \\ 1033 Buenos Aires, Argentina \\ ${ }^{4}$ Gastroenterology Unit, Children Hospital 'Superiora Sor Maria Ludovica', Calle 14 No. 1631, 1900 La Plata, \\ Buenos Aires, Argentina \\ ${ }^{5}$ Institute of Medical Microbiology and Parasitology (IMPAM, UBA-CONICET), School of Medicine, University of Buenos Aires \\ - Argentine National Scientific and Technological Research Council, Paraguay 2155, 1121 Buenos Aires, Argentina \\ (Submitted 4 July 2014 - Final revision received 23 December 2014 - Accepted 26 January 2015 - First published online 12 March 2015)
}

\section{Abstract}

It has been postulated that Helicobacter pylori infection could affect growth and appetite, consequently influencing body weight. Therefore, the association between $H$. pylori infection and the dietary and anthropometric indicators of nutritional status of a paediatric population were investigated. A total of 525 children (aged 4-16 years) who were referred to the gastroenterology unit of the Sor Maria Ludovica Children's Hospital from Buenos Aires, Argentina, were enrolled and completed an epidemiological questionnaire. H. pylori infection was diagnosed using the ${ }^{13} \mathrm{C}$-urea breath test $\left({ }^{13} \mathrm{C}\right.$-UBT). Height and weight were assessed for calculation of anthropometric indicators. Energy and macronutrient intakes were estimated by $24 \mathrm{~h}$ dietary recall. Data analysis was performed using a $\chi^{2}$ test, a Student's $t$ test, a MannWhitney $U$ test and linear and logistic regressions. The prevalence of $H$. pylori infection was $25 \cdot 1 \%$ (with a mean age of $10 \cdot 1$ (sD $3 \cdot 1$ ) years). A tendency towards lower energy, carbohydrate, protein and fat intakes was observed in infected patients; however, it was not associated with $H$. pylori infection in any of the evaluated age groups (4-8,9-13 and 14-16 years). Underweight, stunting, overweight and obesity were also not associated with the infection. Although height-for-age and BMI-for-age $Z$ scores tended to be lower in infected patients, the differences between $H$. pylori-positive and $H$. pylori-negative children were not statistically significant. In conclusion, $H$. pylori infection was not associated with dietary intake or with anthropometric indicators in the present population of children with gastrointestinal symptoms; however, an increased sample size would be needed to confirm the observed tendency towards lower dietary intake and lower anthropometric indicators of nutritional status in $H$. pylori-infected children.

Key words: Helicobacter pylori: Children: Dietary intake: Anthropometric indicators

Helicobacter pylori infection has been linked to the occurrence of several non-gastrointestinal disorders which might have health consequences in the long term ${ }^{(1)}$. Because the infection is mainly acquired during childhood and persists throughout life unless treated, its association with micronutrient deficiencies and growth impairment, along with other extra-gastric conditions, has been postulated ${ }^{(2,3)}$. Although several cross-sectional and cohort studies have demonstrated an association between $H$. pylori infection and growth retardation $^{(4-8)}$, other investigations have not supported this relationship ${ }^{(9-12)}$. Interpretation of the results appears to be complex, because socio-economic factors, sanitary conditions, age, diet and other co-infections are all variables which are independently associated with growth variation ${ }^{(6,13-16)}$. According to the guidelines of the North American and European Societies for Pediatric Gastroenterology, Hepatology and Nutrition ${ }^{(17)}$

Abbreviations: DOB, delta over baseline, ${ }^{13} \mathrm{C}$-UBT, ${ }^{13} \mathrm{C}$-urea breath test; UHR, urea hydrolysis rate.

*Corresponding author: M. A. Janjetic, fax +54 114964 8201, email mjanje@ffyb.uba.ar 
and the Canadian Helicobacter Study Group Consensus Conference ${ }^{(18)}$, there is not sufficient evidence to establish a causative role of $H$. pylori infection for growth retardation.

H. pylori colonisation has also been postulated to influence another aspect related to the modulation of appetite and its consequences in energy homeostasis and body weight. It has been proposed that gastric secretion of ghrelin, an orexigenic hormone produced mainly in the oxyntic mucosa of the stomach ${ }^{(19)}$, could be affected by $H$. pylori infection. A systematic review of the literature published in 2011 concluded that circulating ghrelin levels are lower in H. pylori-infected individuals ${ }^{(20)}$; however, the impacts of H. pylori infection and its eradication on body weight are still controversial. Moreover, studies evaluating dietary intake in $H$. pylori-infected and $H$. pylori-uninfected individuals, particularly children, are scarce. In addition, body weight could also influence the values obtained from the ${ }^{13} \mathrm{C}$-urea breath test $\left({ }^{13} \mathrm{C}\right.$-UBT) for $H$. pylori infection diagnosis. ${ }^{13} \mathrm{C}$-UBT results are usually expressed in terms of breath ${ }^{13} \mathrm{CO}_{2}$ enrichment related to the baseline values (delta over baseline, DOB), and this depends not only on the quantity of exhaled ${ }^{13} \mathrm{CO}_{2}$ but also on the endogenous $\mathrm{CO}_{2}$ production as well. In this sense, a certain quantity of exhaled ${ }^{13} \mathrm{CO}_{2}$ could result in a higher $\mathrm{DOB}$ value for a person who has a lower $\mathrm{CO}_{2}$ production rate (smaller body size) as compared to a person with a higher $\mathrm{CO}_{2}$ production rate (larger body size). Alternatively, the urease activity expressed by the $H$. pylori burden may be independent of body size. In order to normalise these results by the endogenous $\mathrm{CO}_{2}$ production, patients' surface area and BMR should be taken into account along with their DOB values when calculating their urea hydrolysis rates (UHR). ${ }^{13} \mathrm{C}$-UBT has been considered a semi-quantitative method for $H$. pylori diagnosis because DOB values have been related to bacterial load ${ }^{(21)}$. It could be speculated that higher UBT results (normalised as UHR values) are related to lower ghrelin production and consequently to a lower body weight.

The present retrospective cross-sectional study aimed to evaluate the association between $H$. pylori infection and the dietary and anthropometric indicators of nutritional status in a paediatric population with gastrointestinal symptoms from Buenos Aires, Argentina.

\section{Patients and methods}

\section{Patients and ethics}

A total of 525 children aged 4 to 16 years who were referred to the gastroenterology unit of the Superiora Sor Maria Ludovica Children's Hospital in La Plata, Argentina, were included in the present study. The hospital is a tertiary-level health care referral institution with the highest clinical complexity for attending children in Buenos Aires province. Inclusion criteria were the presence of upper gastrointestinal signs and symptoms, such as gastroesophageal reflux, symptoms of oesophagitis, dyspepsia and abdominal pain, and exclusion criteria were the use of antibiotics or acid suppressants during the previous month.

The present study was conducted according to the guidelines laid down in the Declaration of Helsinki, and all procedures involving patients were approved by the ethics committee of the Superiora Sor Maria Ludovica Children's Hospital. Written informed consent was obtained from parents or legal guardians after they read the protocol information. Results on H. pylori infection status and the other measured variables were sent to the responsible health facilities, where children received appropriate treatment

\section{${ }^{13} \mathrm{C}$-urea breath test}

The ${ }^{13} \mathrm{C}$-UBT is a highly accurate test, with values of sensitivity and specificity of more than $95 \%$ for the diagnosis of $H$. pylori infection $^{(22)}$. The test consisted of the following: after at least $6 \mathrm{~h}$ of fasting, children were instructed to exhale air into two hermetically sealed containers (Labco Limited) to determine basal ${ }^{13} \mathrm{C}:{ }^{12} \mathrm{C}$ ratios. Then, $150 \mathrm{ml}$ of reconstituted, powdered, non-fatty milk containing $50 \mathrm{mg}$ of ${ }^{13} \mathrm{C}$-urea (Cambridge Isotope Laboratories, Inc.) was taken by each patient, and two more breath samples were collected, one at $30 \mathrm{~min}$ and another at $45 \mathrm{~min}$ after the ingestion of the labelled solution. Each sample of exhaled air was measured in an isotope ratio mass spectrometer coupled to a gas chromatograph (Finnigan MAT GmbH, Thermo Fisher Scientific). A change of $>3.5 \%$ in the DOB values was considered positive ${ }^{(22)}$. In order to normalise these results by endogenous $\mathrm{CO}_{2}$ production, the UHR was calculated ${ }^{(23)}$ considering the DOB values of each patient and using the following formula:

$$
\mathrm{UHR}(\mu \mathrm{g} / \mathrm{min})=\mathrm{VCO}_{2}(\mathrm{mmol} / \mathrm{min}) \times \mathrm{DOB} \times 0.3463 .
$$

$\mathrm{VCO}_{2}$ was estimated from body surface area using the Schofield equation, which provides an accurate estimate in children ${ }^{(24)}$. Results expressed in terms of UHR could then be compared independent of age, sex or body size.

\section{Dietary assessment}

Energy and macronutrient intakes were assessed with $24 \mathrm{~h}$ dietary recalls administered to the parent or guardian of each child. A book of picture charts was used to aid respondents in portion size estimation ${ }^{(25)}$. Data analysis was performed using the food composition database compiled in 2007 by the Argentine Ministry of Health ${ }^{(26)}$. Information for two non-consecutive days of nutrient intake was obtained from a subsample of 160 children selected by systematic random sampling ${ }^{(27,28)}$. Epidemiological characteristics of the subsample did not differ statistically from the main sample, which meant that it was representative of the entire cohort. Adjustment of nutrient intake was made by calculating within-person and between-person variances using variance analyses (ANOVA) according to the methodology described by the National Research Council, the US National Academy of Sciences ${ }^{(27)}$ and Slater et al. ${ }^{(29)}$ in order to partially remove variation in within-person consumption and to obtain the estimated usual intake distribution for each nutrient. Transformation was applied to nutrient intakes that did not have a normal distribution in order to remove asymmetry, and data were back-transformed to the original scale. 
The prevalence of inadequate intake was estimated by calculating the percentage of the group with usual nutrient intake that was less than the estimated average or the energy requirements recommended by the Food and Nutrition Board of the Institute of Medicine ${ }^{(30,31)}$. Those $24 \mathrm{~h}$ dietary recalls in which energy intake was lower than $2092 \mathrm{~kJ} / \mathrm{d}(500 \mathrm{kcal} / \mathrm{d})$ or higher than $15062.4 \mathrm{~kJ} / \mathrm{d}(3600 \mathrm{kcal} / \mathrm{d})$ were considered to under- or over-report energy intake, respectively, and were consequently excluded from the adjustment ${ }^{(32)}$.

\section{Epidemiological questionnaire}

An epidemiological questionnaire was administered to the parent or guardian of each child in order to obtain information about possible predictive variables for $H$. pylori positivity. The questionnaire was focused on ethnicity, socio-demographic factors and sanitary conditions. Unsatisfied basic needs were defined according to the guidelines of the National Institute of Statistics and Census of Argentina ${ }^{(33)}$, taking into account the following variables: family crowding, type of housing, type of flooring, type of toilet, source of water, education levels of the children, the head of the family and the mother and the number of family members who depend economically of the household head.

\section{Anthropometric indicators}

At enrolment, body weight and height were obtained from each of the participating children in duplicate by the same researcher. Height was recorded using a stadiometer (Stanley)

Table 1. Socio-demographical and sanitary data of the children included in the present study

(Mean values and standard deviations; number of children; percentages)

\begin{tabular}{|c|c|c|c|c|c|}
\hline & H. pylori negative $(n)$ & $\%$ & H. pylori positive $(n)$ & $\%$ & $P$ \\
\hline Overall & 393 & 74.9 & 132 & $25 \cdot 1$ & \\
\hline Age (years) & & & & & 0.24 \\
\hline Mean & $10 \cdot 0$ & & $10 \cdot 3$ & & \\
\hline SD & $3 \cdot 1$ & & $3 \cdot 1$ & & \\
\hline Age group (years) & & & & & 0.60 \\
\hline $4-8$ & 130 & $33 \cdot 1$ & 38 & $28 \cdot 8$ & \\
\hline $9-13$ & 199 & $50 \cdot 6$ & 69 & $52 \cdot 3$ & \\
\hline $14-16$ & 64 & $16 \cdot 3$ & 25 & $18 \cdot 9$ & \\
\hline Sex & & & & & 0.12 \\
\hline Female & 211 & $53 \cdot 7$ & 81 & 61.4 & \\
\hline Male & 182 & $46 \cdot 3$ & 51 & 38.6 & \\
\hline Ethnicity & & & & & $<0.001^{*}$ \\
\hline Caucasian & 367 & 93.4 & 110 & $83 \cdot 3$ & \\
\hline South American Indian & 26 & $6 \cdot 6$ & 22 & $16 \cdot 7$ & \\
\hline Education Level & & & & & $0 \cdot 18$ \\
\hline Kindergarten & 35 & 8.9 & 17 & $12 \cdot 8$ & \\
\hline BGE $\ddagger$ & 335 & $85 \cdot 2$ & 109 & $82 \cdot 6$ & \\
\hline Polimodal§ & 23 & 5.9 & 6 & 4.6 & \\
\hline Place of residence & & & & & $0.02^{*}$ \\
\hline Great BA & 35 & 8.9 & 23 & $17 \cdot 4$ & \\
\hline BA province & 350 & $89 \cdot 0$ & 108 & $81 \cdot 8$ & \\
\hline Other & 8 & $2 \cdot 1$ & 1 & 0.8 & \\
\hline Number of siblings & & & & & $<0.01 \dagger$ \\
\hline None & 62 & $15 \cdot 8$ & 5 & 3.8 & \\
\hline 1 & 139 & 35.4 & 37 & $28 \cdot 0$ & \\
\hline 2 & 107 & $27 \cdot 2$ & 38 & $28 \cdot 8$ & \\
\hline 3 & 45 & 11.5 & 21 & $15 \cdot 9$ & \\
\hline 4 or more & 40 & $10 \cdot 2$ & 31 & 23.5 & \\
\hline Family members in the household & & & & & $<0.01 \dagger$ \\
\hline 2 & 11 & $2 \cdot 8$ & 3 & $2 \cdot 3$ & \\
\hline 3 & 66 & $16 \cdot 8$ & 13 & 9.9 & \\
\hline 4 & 134 & $34 \cdot 1$ & 36 & $27 \cdot 3$ & \\
\hline 5 & 114 & $29 \cdot 0$ & 38 & $28 \cdot 8$ & \\
\hline 6 or more & 68 & $17 \cdot 3$ & 42 & $31 \cdot 8$ & \\
\hline Educational level of the mother & & & & & $<0.01^{\star}$ \\
\hline Incomplete primary school & 11 & $2 \cdot 8$ & 19 & 14.4 & \\
\hline Primary school & 175 & 44.5 & 77 & $58 \cdot 3$ & \\
\hline Secondary school & 114 & $29 \cdot 0$ & 21 & $15 \cdot 9$ & \\
\hline Tertiary or University education & 93 & $23 \cdot 7$ & 15 & 11.4 & \\
\hline UBN & & & & & $<0.01^{\star}$ \\
\hline Yes & 114 & $29 \cdot 0$ & 67 & $50 \cdot 8$ & \\
\hline No & 279 & $71 \cdot 0$ & 65 & $49 \cdot 2$ & \\
\hline
\end{tabular}

BGE, basic general education; Great BA, Great Buenos Aires (suburban areas); BA province, Buenos Aires province (inner city); UBN, unsatisfied basic needs.

${ }^{*}$ Percentages were significantly different between the groups $\left(P<0.05 ; \chi^{2}\right.$ test $)$.

$\dagger$ Percentages were significantly different between the groups $(P<0.05$; Mann-Whitney $U$ test).

†For children aged 6 to 15 years.

$\S$ For children aged 15 to 18 years. 
to the nearest $0 \cdot 1 \mathrm{~cm}$, and weight was measured with a portable mechanical scale (CAM) to the nearest $100 \mathrm{~g}$. Height-, weight- and BMI-for-age were expressed as $Z$ scores, and underweight, stunting, overweight and obesity were defined relative to the age- and sex-appropriate standards in the WHO Growth Charts ${ }^{(34,35)}$. Anthropometric techniques were previously standardised ${ }^{(36)}$, and $z$ scores were calculated by the Anthro and AnthroPlus programmes.

\section{Statistical analysis}

An $\chi^{2}$ test was used to analyse dependency between $H$. pylori positivity and other categorical variables. The normality of the data was assessed using the Shapiro-Wilk test. A Student's $t$ test was used when it was proven that variances were homogeneous; if not, the nonparametric Mann-Whitney $U$ test was applied. A logistic regression was performed to estimate the association between socio-demographic variables and H. pylori status, and crude and adjusted OR were obtained with 95\% CI. Linear regression was used to evaluate the association of $H$. pylori infection status with anthropometric indicators and nutrient intakes, and $\beta$ coefficients were obtained with 95\% CI. Variables associated with $H$. pylori infection which could affect nutrient intake and anthropometric indicators were considered as confounding factors for these parameters. Significance levels were set at $\alpha<0.05$. Statistical analyses were performed using SPSS software version 17.0 (IBM SPSS).

\section{Results}

\section{Epidemiology}

The present study included 525 children (55.6\% females) with a mean age of $10 \cdot 1$ years $(95 \%$ CI 9.8, 10.3). The response rate was $100 \%$. A total of 132 patients were found to be H. pylori-positive by means of the ${ }^{13} \mathrm{C}$-UBT, which correlated to a prevalence of $25 \cdot 1 \%(95 \%$ CI $21 \cdot 5,29 \cdot 5)$ in this symptomatic population. All of the patients completed the epidemiological questionnaire. There were no statistically significant differences in terms of demographic variables, such as mean age $(P=0 \cdot 24)$ and age groups $(P=0 \cdot 60)$, sex $(P=0 \cdot 12)$ and education level of the children $(P=0 \cdot 18)$, between $H$. pylori-positive and H. pylori-negative patients (Table 1 ).

The variables which proved to be associated to $H$. pylori infection included ethnicity $(P<0 \cdot 001)$, with a higher prevalence in South American Indians, place of residence $(P=0.02)$, a higher number of siblings $(P<0 \cdot 01)$ and family members $(P<0 \cdot 01)$ in the household, a lower education level of the mother and the head of the family $(P<0 \cdot 01)$, unsatisfied basic needs $(P<0 \cdot 01)$ (Table 1$)$ and poorer sanitary conditions, as denoted by the type of flooring $(P<0 \cdot 01)$ and the type of toilet $(P<0 \cdot 01)$, where a cement or soil floor and a pit latrine toilet were associated with $H$. pylori infection. After adjusting for confounding factors, the remaining predictive variables for H. pylori positivity were ethnicity (OR 2.08, $95 \%$ CI 1.09, 3.97), number of siblings (OR 1.21, 95\% CI 1.07, 1.38), education level of the mother (OR $0.53,95 \%$ CI $0.33,0.86$ ) and type of flooring (OR 1.99, $95 \%$ CI 1.27, 3·12).

\section{Food intake}

Dietary recalls were collected from all of the participating children. We excluded from the analysis six $24 \mathrm{~h}$ recalls due to under-reporting and fifteen recalls due to over-reporting of energy intake. The prevalence of inadequate energy intake was $42 \%$ in the whole population, with no significant differences according to $H$. pylori infection or age group $(P=0 \cdot 34)$. Table 2 summarises the macronutrient and energy intakes according to $H$. pylori status in the different age groups. Energy, carbohydrate, protein and fat intakes were not associated with $H$. pylori infection either by age or by sex. The association between $H$. pylori infection status alone and infection status adjusted by confounders and nutrient intake is shown in Table 3. Fat intake was observed to be affected by $H$. pylori infection $(P=0.02)$; however, this result was no longer significant after adjustment $(P=0 \cdot 08)$.

\section{Anthropometric indicators}

When analysing the anthropometric indicators as quantitative variables, height-for-age $Z$ score values and BMI-for-age

Table 2. Nutrient intake in the different age groups according to Helicobacter pylori infection (Mean values and standard deviations)

\begin{tabular}{|c|c|c|c|c|c|c|}
\hline \multirow[b]{2}{*}{ Age group (years) } & \multirow[b]{2}{*}{ Nutrient intake } & \multicolumn{2}{|c|}{ H. pylori negative } & \multicolumn{2}{|c|}{ H. pylori positive } & \multirow[b]{2}{*}{$P$} \\
\hline & & Mean & SD & Mean* & SD & \\
\hline \multirow[t]{4}{*}{$4-8$} & Energy $(\mathrm{kJ} / \mathrm{d})$ & $7068 \cdot 6$ & $2178 \cdot 4$ & $6361 \cdot 8$ & 1863.5 & 0.07 \\
\hline & Carbohydrate $(\mathrm{g} / \mathrm{d})$ & $214 \cdot 3$ & $50 \cdot 0$ & $204 \cdot 3$ & $47 \cdot 7$ & 0.30 \\
\hline & Protein (g/d) & 57.8 & $15 \cdot 3$ & $52 \cdot 7$ & $12 \cdot 8$ & 0.06 \\
\hline & Fat $(g / d)$ & $59 \cdot 8$ & $6 \cdot 7$ & $57 \cdot 7$ & $5 \cdot 8$ & 0.08 \\
\hline \multirow[t]{4}{*}{$9-13$} & Energy $(\mathrm{kJ} / \mathrm{d})$ & 7998.9 & $2511 \cdot 2$ & $7473 \cdot 0$ & $2489 \cdot 1$ & 0.14 \\
\hline & Carbohydrate $(\mathrm{g} / \mathrm{d})$ & $232 \cdot 3$ & $60 \cdot 9$ & $222 \cdot 3$ & 57.5 & 0.25 \\
\hline & Protein $(\mathrm{g} / \mathrm{d})$ & $61 \cdot 2$ & $7 \cdot 0$ & $60 \cdot 9$ & $7 \cdot 0$ & 0.82 \\
\hline & Fat $(\mathrm{g} / \mathrm{d})$ & $62 \cdot 2$ & $7 \cdot 1$ & $60 \cdot 4$ & $7 \cdot 0$ & $0 \cdot 10$ \\
\hline \multirow[t]{4}{*}{$14-16$} & Energy (kJ/d) & $7820 \cdot 9$ & $2809 \cdot 3$ & $8177 \cdot 2$ & $2555 \cdot 2$ & 0.59 \\
\hline & Carbohydrate $(g / d)$ & 228.0 & $62 \cdot 8$ & $249 \cdot 3$ & 61.5 & 0.17 \\
\hline & Protein $(\mathrm{g} / \mathrm{d})$ & 64.9 & $18 \cdot 3$ & 64.4 & $16 \cdot 5$ & 0.90 \\
\hline & Fat $(\mathrm{g} / \mathrm{d})$ & $61 \cdot 6$ & $7 \cdot 2$ & $60 \cdot 3$ & $7 \cdot 7$ & 0.47 \\
\hline
\end{tabular}

* Mean values were not significantly different from those of the $H$. pylori-negative group $(P>0.05$; Mann-Whitney $U$ test $)$. 
Table 3. Crude and adjusted $\beta$ coefficients for nutrient intake and anthropometric indicators according to Helicobacter pylori infection

( $\beta$ Coefficients and $95 \%$ confidence intervals)

\begin{tabular}{lcccccc}
\hline Indicator & Crude $\beta$ & $95 \% \mathrm{Cl}$ & $P$ & Adjusted $\beta$ & $95 \% \mathrm{Cl}$ & $P$ \\
\hline Energy intake $(\mathrm{kJ} / \mathrm{d})$ & -383.35 & $-878.6,115.9$ & 0.13 & $-340.6 \dagger$ & $-846.0,164.8$ & 0.18 \\
Carbohydrate intake $(\mathrm{g} / \mathrm{d})$ & -3.2 & $-15.1,8.8$ & 0.60 & $-5.6 \dagger$ & $-17.8,6.5$ & 0.36 \\
Protein intake $(\mathrm{g} / \mathrm{d})$ & -1.3 & $-4.0,1.0$ & 0.25 & $-1.1 \dagger$ & $-3.6,1.5$ & 0.42 \\
Fat intake $(\mathrm{g} / \mathrm{d})$ & -1.8 & $-3.2,-0.3$ & $0.02^{*}$ & $-1.3 \dagger$ & $-2.8,0.1$ & 0.08 \\
Height-for-age $(Z$ score $)$ & -0.2 & $-0.4,-0.01$ & $0.04^{*}$ & $-0.1 \ddagger$ & $-0.4,0.1$ & 0.20 \\
BMl-for-age $(Z$ score $)$ & -0.2 & $-0.4,0.1$ & 0.20 & $-0.04 \ddagger$ & $-0.3,0.2$ & 0.78 \\
\hline
\end{tabular}

${ }^{*}$ Crude $\beta$ coefficients were significantly different between the groups $(P<0.05$; linear regression)

$\dagger$ Adjustment by number of siblings, unsatisfied basic needs, ethnicity, sex and age.

$\ddagger$ Adjustment by number of siblings, unsatisfied basic needs, ethnicity and protein intake.

$Z$ score values were lower within the infected children $(-0 \cdot 38$, $95 \% \mathrm{CI}-0 \cdot 55,-0 \cdot 19$ and $-0 \cdot 02,95 \% \mathrm{CI}-0 \cdot 24,-0 \cdot 20)$ than they were in the uninfected group $(-0 \cdot 17,95 \%$ CI $-0 \cdot 26$, -0.06 and $0.12,95 \% \mathrm{CI}-0.01,0.25)$. Results for the anthropometric indicators showed a significantly lower height-forage $Z$ score in $H$. pylori-infected children (Table 3), but these scores were not significant after multiple variable analyses.

Table 4 summarises the anthropometric nutritional status of the children according to $H$. pylori infection. The prevalence of underweight, normal weight, stunting, overweight and obesity did not differ significantly between the infected and the uninfected children

\section{${ }^{13} \mathrm{C}$-urea breath test results and anthropometric nutritional status}

${ }^{13} \mathrm{C}$-UBT results were normalised by endogenous $\mathrm{CO}_{2}$ production through calculation of the UHR. In the H. pylori positive group, UHR values were significantly higher in children with underweight or normal weight $(P=0 \cdot 02)$, but in the H. pylori negative group, no significant difference in UHR could be found between children between underweight-normal weight and overweight-obesity $(P=0.66)$. Neither DOB nor its normalised variable UHR differed in terms of their association with the anthropometric indicators of nutritional status.

\section{Discussion}

It has been postulated that $H$. pylori infection could affect dietary intake; however, studies that have investigated this relationship are limited. We aimed to evaluate the association between $H$. pylori positivity and the dietary and anthropometric indicators of nutritional status in children with gastrointestinal symptoms. The nature of the sample, which was represented exclusively by symptomatic children, should be taken into consideration as a limitation of the present results. In addition, sources of measurement error in the $24 \mathrm{~h}$ dietary recall, the method we used for dietary assessment in the present epidemiological study, should also be considered; in particular, the parents or guardians of the children could have unintentionally misreported dietary intakes ${ }^{(32)}$.

We found a higher prevalence of inadequate energy intake in the present population than that reported by the Argentine National Questionnaire of Nutrition and Health ${ }^{(37)}$, in which $24 \mathrm{~h}$ dietary recalls were also used for dietary assessment. Because a lower mean energy intake has been described for dyspeptic children regardless of the presence of $H$. pylori infection $^{(38)}$, the lower intake could have been related to the presence of gastric symptoms in all of the children, representing a population bias. After a quantitative analysis of the dietary intakes in the present study, we did not find any significant differences in the mean values of the energy, carbohydrates, proteins and fat intakes between the H. pyloriinfected and the $H$. pylori-uninfected children for any of the evaluated age groups (Table 2). However, a tendency towards lower intakes for all of the evaluated nutrients could be evidenced by the $\beta$ coefficients described in Table 3. Moreover, fat intake was significantly lower in H. pylori-positive children, although this was no longer significant after adjustment for confounders. Sample size could have been another variable that limited the present results. In order to evaluate whether the observed tendency towards lower dietary intakes in $H$. pylori-positive children results in a significant difference, a higher number of subjects should be studied to increase the power of the study; in the present study, a $40 \%$ power was obtained from a retrospective power calculation based

Table 4. Anthropometric indicators of nutritional status according to Helicobacter pylori infection (Percentages and $95 \%$ confidence intervals)

\begin{tabular}{lccccc}
\hline Nutritional status & H. pylori negative (\%) & $95 \% \mathrm{Cl}$ & H. pylori positive (\%) & $95 \% \mathrm{Cl}$ & $P$ \\
\hline Underweight & 6.7 & $4.5,9.5$ & 5.3 & $2 \cdot 6,6.5$ & 0.57 \\
Normal weight & 66.6 & $61.8,71 \cdot 1$ & 68.9 & $60.6,76.2$ & 0.47 \\
Stunting & 3.3 & $1.9,5 \cdot 6$ & 4.5 & $2 \cdot 1,9.6$ & 0.52 \\
Overweight & 14.5 & $11.3,18 \cdot 3$ & 15.2 & $10.0,22 \cdot 2$ & 0.88 \\
Obesity & 8.9 & $6.5,12 \cdot 1$ & 6.1 & $3 \cdot 1,11.5$ & 0.29 \\
\hline
\end{tabular}

*Percentages were not significantly different between the groups $\left(P>0.05 ; \chi^{2}\right.$ test $)$. 
on mean differences in energy intake. On the other hand, the present results showed that anthropometric indicators of nutritional status did not differ significantly between infected and uninfected children with digestive symptomatology (Table 4). Future studies should be conducted to evaluate the anthropometric indicators of nutritional status in asymptomatic children with or without the infection.

It has been postulated that values from the ${ }^{13} \mathrm{C}$-UBT are related to $H$. pylori bacterial load ${ }^{(21)}$. It could be speculated that higher UBT results (normalised as UHR values) may be associated with lower ghrelin production and consequently with lower body weight. In the present study, we investigated whether UHR could be associated with anthropometric indicators of nutritional status and obtained significantly higher UHR values for the H.pylori-positive children with underweight or normal weight $(P=0 \cdot 02)$. Nevertheless, measurements of circulating ghrelin levels as well as histological affection of the gastric mucosa should be evaluated in order to confirm these results. Because the $H$. pylori genotype and virulence factors, such as the presence of the cag pathogenicity island, are related to the severity of gastric disease ${ }^{(39)}$, these variables should also be evaluated.

Growth is a complex phenomenon that is influenced by multiple factors. In the present study, we did not find an association between $H$. pylori infection and growth-related anthropometric indicators; however, we did observe a tendency towards lower $Z$ scores for the anthropometric indicators evaluated in the $H$. pylori-infected children. Moreover, significant differences that were obtained for height-for-age $Z$ scores in the $H$. pylori-positive group were no longer significant after adjustment for confounders, and this is consistent with findings from other cross-sectional studies ${ }^{(9-12)}$. Cohort studies evaluating the effect of $H$. pylori on growth retardation have reported controversial results ${ }^{(5,7,12,40-42)}$. Although growth velocity has been found to be impaired in H. pylori-positive infants and children from Colombia and Ecuador ${ }^{(5,7,40,41)}$, reports on children from other areas have not found the same effect ${ }^{(12)}$. Evaluation of the long-term effects on growth after $H$. pylori infection has been resolved suggests that the growth of children benefits when they are treated for $H$. pylori infection ${ }^{(8)}$. However, it has been reported that a BMI decrease is also related to the presence of recurrent abdominal pain associated with gastric lesions, independent of the presence of $H$. pylori infection ${ }^{(43)}$.

In conclusion, predictive variables for $H$. pylori positivity included ethnicity, number of siblings, education level of the mother and type of flooring. H. pylori infection was not associated with dietary intake or with anthropometric indicators in children with gastrointestinal symptoms; however, an increased sample size would be needed to confirm the observed tendencies towards lower dietary intake and anthropometric indicators in $H$. pylori-infected children.

\section{Acknowledgements}

We thank Professor Dr Tom Preston from the Stable Isotope Biochemistry Laboratory, The University of Glasgow, for kindly reviewing the final version of the present manuscript.
The present work was supported by the University of Buenos Aires (UBA) (C. G. G., Project UBACyT 20020100100837) and the International Atomic Energy Agency (IAEA) (C. G. G., Coordinated Research Programme ARG-16746). UBA and IAEA had no role in the design, analysis or writing of the present article.

The authors' contributions are as follows: M. B. Z., J. R. B. and C. G. G. formulated the research questions and designed the study; M. A. J., P. M., E. C. R., N. B., G. Z. d. P. and M. C. conducted the research; M. A. J. and P. M. performed the statistical analysis; M. A. J., P. M. and C. G. G. wrote the article. All authors have read and approved the final manuscript.

None of the authors has any conflicts of interest to declare.

\section{References}

1. Roubaud Baudron C, Franceschi F, Salles N, et al. (2013) Extragastric diseases and Helicobacter pylori. Helicobacter 18, Suppl. 1, S44-S51.

2. Akcam M (2011) Helicobacter pylori and micronutrients. Indian Pediatr 47, 119-126.

3. Queiroz DM, Rocha AM \& Crabtree JE (2013) Unintended consequences of Helicobacter pylori infection in children in developing countries: iron deficiency, diarrhea, and growth retardation. Gut Microbes 4, 494-504.

4. Richter T, Richter T, List S, et al. (2001) Five- to 7-year-old children with Helicobacter pylori infection are smaller than Helicobacter-negative children: a cross-sectional population-based study of 3,315 children. J Pediatr Gastroenterol Nutr 33, 472-475.

5. Mera RM, Correa P, Fontham EE, et al. (2006) Effects of a new Helicobacter pylori infection on height and weight in Colombian children. Ann Epidemiol 16, 347-351.

6. Vilchis J, Duque X, Mera R, et al. (2009) Association of Helicobacter pylori infection and height of Mexican children of low socioeconomic level attending boarding schools. Am J Trop Med Hyg 81, 1091-1096.

7. Goodman KJ, Correa P, Mera R, et al. (2011) Effect of Helicobacter pylori infection on growth velocity of school-age Andean children. Epidemiology 22, 118-126.

8. Mera RM, Bravo LE, Goodman KJ, et al. (2012) Long-term effects of clearing Helicobacter pylori on growth in schoolage children. Pediatr Infect Dis J 31, 263-266.

9. Leandro Liberato SV, Hernandez Galindo M, Torroba Alvarez L, et al. (2005) Helicobacter pylori infection in the child population in Spain: prevalence, related factors and influence on growth. An Pediatr (Barc) 63, 489-494.

10. Chi H, Bair MJ, Wu MS, et al. (2009) Prevalence of Helicobacter pylori infection in high-school students on Lanyu Island, Taiwan: risk factor analysis and effect on growth. J Formos Med Assoc 108, 929-936.

11. Cherian S, Forbes D, Sanfilippo F, et al. (2009) Helicobacter pylori, helminth infections and growth: a cross-sectional study in a high prevalence population. Acta Paediatr $\mathbf{9 8}$, 860-864.

12. Chimonas MA, Baggett HC, Parkinson AJ, et al. (2006) Asymptomatic Helicobacter pylori infection and iron deficiency are not associated with decreased growth among Alaska Native children aged 7-11 years. Helicobacter 11, 159-167.

13. Sood MR, Joshi S, Akobeng AK, et al. (2005) Growth in children with Helicobacter pylori infection and dyspepsia. Arch Dis Child 90, 1025-1028.

14. Ozen A, Furman A, Berber M, et al. (2011) The effect of Helicobacter pylori and economic status on growth 
parameters and leptin, ghrelin, and insulin-like growth factor (IGF)-I concentrations in children. Helicobacter $\mathbf{1 6}$ $55-65$.

15. Fialho AM, Braga AB, Queiroz DM, et al. (2007) The association between Helicobacter pylori infection and height in children from an urban community in north-east Brazil. Ann Trop Paediatr 27, 55-61.

16. Quinonez JM, Chew F, Torres O, et al. (1999) Nutritional status of Helicobacter pylori-infected children in Guatemala as compared with uninfected peers. Am J Trop Med Hyg 61, 395-398.

17. Koletzko S, Jones NL, Goodman KJ, et al. (2011) Evidencebased guidelines from ESPGHAN and NASPGHAN for Helicobacter pylori infection in children. I Pediatr Gastroenterol Nutr 53, 230-243.

18. Bourke B, Ceponis P, Chiba N, et al. (2005) Canadian Helicobacter Study Group Consensus Conference: update on the approach to Helicobacter pylori infection in children and adolescents-an evidence-based evaluation. Can J Gastroenterol 19, 399-408.

19. Date Y, Kojima M, Hosoda H, et al. (2000) Ghrelin, a novel growth hormone-releasing acylated peptide, is synthesized in a distinct endocrine cell type in the gastrointestinal tracts of rats and humans. Endocrinology 141, 4255-4261.

20. Nweneka CV \& Prentice AM (2011) Helicobacter pylori infection and circulating ghrelin levels - a systematic review. BMC Gastroenterol 11, 7.

21. Ellenrieder V, Glasbrenner B, Stoffels C, et al. (1997) Qualitative and semi-quantitative value of a modified ${ }^{13} \mathrm{C}$-urea breath test for identification of Helicobacter pylori infection. Eur J Gastroenterol Hepatol 9, 1085-1089.

22. Leal YA, Flores LL, Fuentes-Panana EM, et al. (2011) ${ }^{13} \mathrm{C}$-urea breath test for the diagnosis of Helicobacter pylori infection in children: a systematic review and meta-analysis. Helicobacter 16, 327-337.

23. Slater C, Preston T \& Weaver LT (2004) Is there an advantage in normalising the results of the Helicobacter pylori ${ }^{13} \mathrm{C}$-urea breath test for $\mathrm{CO}_{2}$ production rate in children? Isotopes Environ Health Stud 40, 89-98.

24. Rodriguez G, Moreno L, Sarria A, et al. (2000) Resting energy expenditure in children and adolescents: agreement between calorimetry and prediction equations. Clin Nutr 21, 255-260.

25. Avila T \& Chiappe C (2007) Atlas fotográfico de preparaciones de alimentos (Photographic Food Atlas), 1st ed., pp. 1-19, [T Avila and C Chiappe, editors]. Buenos Aires: Akadia.

26. Ministerio de Salud y Ambiente de la Nación Argentina, Programa Materno Infantil (2006) Sistema de Análisis y Registro de Alimentos (Food Analysis and Registration System), SARA. http://www.msal.gov.ar/promin/archivos/htm/descarga-sara. htm (accessed September 2014)

27. National Research Council (1986) Nutrient Adequacy: Assessment Using Food Consumption Surveys. Report of the Food and Nutrition Board. Washington, DC: National Academy of Sciences.
28. Hoffmann K, Boeing H, Dufour A, et al. (2002) Estimating the distribution of usual dietary intake by short-term measurements. Eur J Clin Nutr 56, Suppl. 2, S53-S62.

29. Slater B, Marchioni DL \& Fisberg RM (2004) Estimating prevalence of inadequate nutrient intake. Rev Saude Publica 38, 599-605.

30. Institute of Medicine, Food and Nutrition Board (2000) Dietary Reference Intakes: Applications in Dietary Assessment. Washington, DC: National Academies Press.

31. Institute of Medicine, Food and Nutrition Board (2005) Dietary Reference Intakes for Energy, Carbohydrate, Fiber, Fat, Fatty Acids, Cholesterol, Protein, and Amino Acids. Washington, DC: National Academies Press.

32. Willett W (1998) Issues in analysis and presentation of dietary data. In Nutritional Epidemiology, 2nd ed., pp. 321-346 [W Willet, editor]. New York, NY: Oxford University Press.

33. National Institute of Statistics and Census of Argentina (INDEC) (2010) http://www.indec.gov.ar/indicadoressociodemograficos.asp (accessed September 2014)

34. WHO Multicentre Growth Reference Study Group (2006) WHO Child Growth Standards based on length/height, weight and age. Acta Paediatr Suppl 450, 76-85.

35. de Onis M, Onyango AW, Borghi E, et al. (2007) Development of a WHO growth reference for school-aged children and adolescents. Bull World Health Organ 85, 660-667.

36. Habicht JP (1974) [Standardization of quantitative epidemiological methods in the field]. Bol Oficina Sanit Panam 76, 375-384.

37. Ministerio de Salud y Ambiente de la Nación, Argentina (2007) Encuesta Nacional de Nutrición y Salud. Documento de Resultados 2007 (National Survey on Health and Nutrition. Document of Results 2007). Buenos Aires: Ministerio de Salud. http://www.msal.gov.ar/htm/site/ennys/pdf/documento_ resultados_2007.pdf (accessed September 2014).

38. Soylu OB \& Ozturk Y (2008) Helicobacter pylori infection: effect on malnutrition and growth failure in dyspeptic children. Eur J Pediatr 167, 557-562.

39. Rick JR, Goldman M, Semino-Mora C, et al. (2019) In situ expression of cagA and risk of gastroduodenal disease in Helicobacter pylori infected children. J Pediatr Gastroenterol Nutr 50, 167-172.

40. Bravo LE, Mera R, Reina JC, et al. (2003) Impact of Helicobacter pylori infection on growth of children: a prospective cohort study. J Pediatr Gastroenterol Nutr 37, 614-619.

41. Egorov AI, Sempertegui F, Estrella B, et al. (2010) The effect of Helicobacter pylori infection on growth velocity in young children from poor urban communities in Ecuador. Int $J$ Infect Dis 14, 788-791.

42. Thomas JE, Dale A, Bunn JE, et al. (2004) Early Helicobacter pylori colonisation: the association with growth faltering in The Gambia. Arch Dis Child 89, 1149-1154.

43. Gulcan M, Ozen A, Karatepe HO, et al. (2010) Impact of H. pylori on growth: is the infection or mucosal disease related to growth impairment? Dig Dis Sci 55, 2878-2886. 